\title{
The rank-heat plot is a novel way to present the results from a network meta-analysis including multiple outcomes
}

\author{
Areti Angeliki Veroniki, Sharon E. Straus, Alexandros Fyraridis, \\ and Andrea C. Tricco
}

\begin{abstract}
Version Post-print/Accepted Manuscript
Citation Veroniki AA, Straus SE, Fyraridis A, Tricco AC, The rank-heat plot is a (published version) novel way to present the results from a network meta-analysis including multiple outcomes, Journal of Clinical Epidemiology (2016), doi: 10.1016/j.jclinepi.2016.02.016.

Copyright/License

(c) (i) $\ominus$ This work is licensed under the Creative Commons

BY NC ND Attribution-NonCommercial-NoDerivatives 4.0

International License. To view a copy of this license, visit http://creativecommons.org/licenses/by-nc-nd/4.0/.
\end{abstract}

How to cite TSpace items

Always cite the published version, so the author(s) will receive recognition through services that track citation counts, e.g. Scopus. If you need to cite the page number of the author manuscript from TSpace because you cannot access the published version, then cite the TSpace version in addition to the published version using the permanent URI (handle) found on the record page.

This article was made openly accessible by $U$ of $T$ Faculty. Please tell us how this access benefits you. Your story matters. 


\section{Accepted Manuscript}

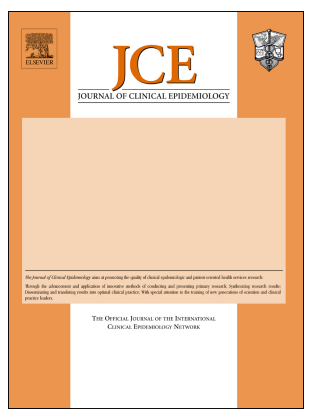

The rank-heat plot is a novel way to present the results from a network meta-analysis including multiple outcomes

Areti Angeliki Veroniki, Sharon E. Straus, Alexandros Fyraridis, Andrea C. Tricco

PII: S0895-4356(16)00153-0

DOI: $\quad$ 10.1016/j.jclinepi.2016.02.016

Reference: JCE 9110

To appear in: Journal of Clinical Epidemiology

Received Date: 25 June 2015

Revised Date: 15 January 2016

Accepted Date: 2 February 2016

Please cite this article as: Veroniki AA, Straus SE, Fyraridis A, Tricco AC, The rank-heat plot is a novel way to present the results from a network meta-analysis including multiple outcomes, Journal of Clinical Epidemiology (2016), doi: 10.1016/j.jclinepi.2016.02.016.

This is a PDF file of an unedited manuscript that has been accepted for publication. As a service to our customers we are providing this early version of the manuscript. The manuscript will undergo copyediting, typesetting, and review of the resulting proof before it is published in its final form. Please note that during the production process errors may be discovered which could affect the content, and all legal disclaimers that apply to the journal pertain. 


\section{The rank-heat plot is a novel way to present the results from a network meta-analysis including multiple outcomes}

Areti Angeliki Veroniki ${ }^{1}$; e-mail: veronikia@smh.ca

Sharon E. Straus ${ }^{1,2}$; e-mail: sharon.straus@ utoronto.ca

Alexandros Fyraridis ${ }^{1}$; e-mail: fyraridisa@ smh.ca

Andrea C. Tricco ${ }^{1,3}$; e-mail: triccoa@smh.ca

${ }^{1}$ Li Ka Shing Knowledge Institute, St. Michael's Hospital, 209 Victoria Street, East Building, Toronto, Ontario, M5B 1T8;

${ }^{2}$ Department of Geriatric Medicine, University of Toronto, Toronto, Ontario;

${ }^{3}$ Epidemiology Division, Dalla Lana School of Public Health, University of Toronto, 155 College Street, 6th floor, Toronto, Ontario, M5T 3M7, Canada

\section{Corresponding Author:}

Dr. Andrea C. Tricco MSc, PhD, Scientist at the Knowledge Translation program, Li Ka Shing Knowledge Institute, St. Michael's Hospital 209 Victoria Street, East Building, Toronto, Ontario, M5B 1T8, Canada. Phone: 416-8646060 extension: 77521, fax: 416-8646057, e-mail: triccoa@smh.ca 


\section{Abstract}

Words: 178 (max 200)

Objective: To present a novel and simple graphical approach to improve the presentation of the treatment ranking in a network meta-analysis (NMA) including multiple outcomes.

Study Design and Settings: NMA simultaneously compares many relevant interventions for a clinical condition from a network of trials, and allows ranking of the effectiveness and/or safety of each intervention. There are numerous ways to present the NMA results, which can challenge their interpretation by research users. The rank-heat plot is a novel graph that can be used to quickly recognize which interventions are most likely the best or worst interventions with respect to their effectiveness and/or safety for a single or multiple outcome(s), and may increase interpretability.

Results: Using empirical NMAs, we show that the need for a concise and informative presentation of results is imperative, particularly as the number of competing treatments and outcomes in a NMA increases.

Conclusions: The rank-heat plot is an efficient way to present the results of ranking statistics, particularly when a large amount of data is available, and it is targeted to users from various backgrounds.

Keywords: multiple treatment meta-analysis; multiple outcomes; probability best; SUCRA; graphical displays; presentation results

Words: 4,696 


\section{What is new?}

- A particularly useful feature of network meta-analysis (NMA) is the ability to rank the effectiveness and safety of each intervention in the model for each outcome.

- There are numerous ways to present the results of a NMA, which can challenge the interpretation by research users. Another challenge is the multitude of results from the NMA, which makes it difficult to present all of the data in a single table or figure in a way that is easy to interpret by the readers.

- We propose the rank-heat plot, a novel and simple graphical approach to improve the presentation of results from the treatment ranking analysis for multiple outcomes.

- The rank-heat plot can be used to quickly recognize what are most likely the best and worst interventions with respect to their effectiveness and/or safety in a single or multiple outcome(s), and can identify treatments that have not been studied with regard to particular outcomes.

- Clinicians can use the rank-heat plot to discuss which agent is optimal across the different outcomes with their patients, guideline developers can use it to inform their recommendations, as can policy makers decide about drug coverage. 


\section{Introduction}

Network meta-analysis (NMA) allows the synthesis of data from a network of randomised controlled trials facilitating the simultaneous comparison of many interventions for managing a specific clinical condition. The advantages of NMA (e.g., ranking multiple competing interventions according to their effectiveness and/or safety [13]) have increased its application over the last two decades [4]. However, there are numerous ways to present NMA results [5-9], and this variation makes their interpretation difficult for research users [10]. Presentation of NMA results becomes even more challenging when large numbers of interventions and outcomes are included. Since the treatment ranking might vary across different outcomes, it is necessary to include all NMA results to make an informed decision about the 'best' available treatment. Several graphical displays have been suggested to present the ranking results of all competing treatments evaluated in a NMA. Hawkins et al [11] were early proponents of presenting the ranking of treatments in a plot (which we later call the 'bubble plot') showing the probability of each treatment being the most effective, the second most effective, etc. Cipriani et al [12] used rankograms to present the distribution of probabilities of each treatment being ranked at each of the possible positions. Salanti et al [5] developed two alternative ways to graphically depict the treatment ranking to facilitate presentation and interpretation of NMA results, including the stacked bar plots and the cumulative ranking probability plots. The latter authors also suggested the use of the surface under the cumulative ranking (SUCRA) curve as an alternative way to rank the treatments, which was a significant advancement in summarizing the NMA findings [5]. Tan et al [7] have proposed the summary forest plot matrix, displaying the NMA and pairwise meta-analysis treatment effect estimates, the heterogeneity estimates, and the ranking and probability best statistics. The authors suggest that pie and rank charts can be used as complementary methods to the summary forest plot matrix to visually summarize the intervention ranking. An approach to summarize the NMA findings of more than one outcome has previously been presented in rankograms, where types of lines correspond to different outcomes [12]. Two-dimensional scatterplots have also been presented in the literature to depict the ranking of treatments for two different outcomes $[6,13]$. However, to the best of our knowledge, there no graphical tools available to summarize the ranking statistics of all studied NMA outcomes in a single plot.

The aim of this study is to present a novel and simple graphical approach to improve the presentation of results from the treatment ranking for multiple outcomes in NMA. We also discuss approaches that have been suggested to present treatment ranking.

\section{Datasets}

We use three previously published systematic reviews and NMAs to present different approaches for the graphical representation of the ranking statistics. The illustrative examples represent small (3 outcomes and eight treatments [14]), medium (5 
outcomes and 15 treatments [15, 16], and large (5 outcomes and 30 treatments [17]) databases with respect to the number of treatments and outcomes studied in NMA. Details of these datasets are provided in Text S1 in Supporting Information.

\section{Graphical tools for treatment ranking}

Different graphical displays have been developed to present the ranking results of all competing treatments included in a network. In this paper, we present the graphical approaches for treatment ranking that have been used in published NMAs [4]. The NMA findings can be summarized using the following statistics: 1) mean/median treatment ranking, 2) probability for each treatment in a NMA being the best (P(best)), and 3) the surface under the cumulative ranking (SUCRA) curve.

\section{Plots for a single outcome}

Most graphical tools, including pie charts, rank charts, rankograms, bar plots, bubble plots, and SUCRA plots can present ranking statistics for a single outcome. Pie and rank charts can be produced when SUCRAs, P(best), or median/mean rankings are available for a specific outcome. Rankograms, bar plots, bubble plots, and SUCRA plots can only be produced when all ranking probabilities for each treatment being considered at each position are available for each outcome.

\section{Pie chart}

A pie chart can graphically depict the treatment ranking in a NMA. The area of the circle in a pie chart is divided into $\mathrm{T}$ different parts, with $\mathrm{T}$ number of treatments in the network. Each region is proportional to the respective ranking probability. The bigger the segment, the better the ranking of the treatment for that outcome.

In Figure S1a we present the probability for each long-acting inhaled agent being the safest for chronic obstructive pulmonary disease (COPD) with respect to arrhythmia. This suggests that salmeterol/fluticasone is most likely the best with $38.98 \%$ probability to rank first, whereas formoterol/budesonide is the least likely to rank first (probability $=0.58 \%$ ).

\section{Rank chart}

In the rank chart [7], the treatments are ordered from greatest to lowest probability of being the best. In Figure S1b we present the treatment order according to P(best) for arrhythmia for the COPD NMA, using a color intensity scheme to highlight what is most likely the best treatment. The colored rank chart uses light grey at the top of the chart with the highest $\mathrm{P}$ (best) and dark grey at the bottom of the chart to indicate the lowest $\mathrm{P}$ (best).

\section{Rankogram}

A rankogram is a two-way plot that shows the ranking probabilities of a treatment on the $\mathrm{y}$-axis that correspond to each of the $\mathrm{T}$ positions presented on the $\mathrm{x}$-axis [12]. For a 
specific treatment and outcome, connecting the probabilities against the rank positions yields a rankogram. The greater the curve bends near the origin, the better the treatment.

In Figure S2, the ranking probabilities are presented for each of the 12 COPD longacting inhaled agents for each of the 12 possible positions. The rankograms summarize the expected rank order of the treatments included in the arrhythmia network. Salmeterol/fluticasone is most likely the safest, as it is associated with the largest probabilities among all 12 competitors to rank at the first treatment position and has the higher curve near the origin. In contrast, vilanterol/fluticasone has a $3.46 \%$ probability to rank $1^{\text {st }}$, and is associated with the highest probability (68.59\%) among all competing treatments to rank $12^{\text {th }}$.

\section{Stacked bar plot}

Stacked bar plots show the corresponding probabilities for the treatments involved in a network to rank at each of the $\mathrm{T}$ positions. On the $\mathrm{x}$-axis, the $\mathrm{T}$ ranking positions are presented, and on the $y$-axis, the ranking probabilities are shown. Each vertical bar depicts the probabilities of the $\mathrm{T}$ treatments being at the specific rank position. Each treatment uses a portion of the bar proportional to the probability of being at the corresponding rank position. The greater the area in a bar, the higher the probability of the treatment being at the corresponding rank position [5].

In Figure S3, we present the ranking probabilities for the 12 long-acting inhaled agents using a stacked bar plot. Salmeterol/fluticasone is most likely the safest treatment, as it yields the largest area in the bar that corresponds to rank 1 with respect to arrhythmia. Contrastingly, vilanterol/fluticasone yields a small probability $(3.46 \%)$ to rank $1^{\text {st }}$ corresponding to a small area of the first bar, whereas it is most likely the least safe as indicated by the largest area for the $12^{\text {th }}$ bar.

\section{Bubble plots}

A bubble plot shows the ranking for all treatments at each possible rank and presents $\mathrm{T}$ possible ranking positions on the $\mathrm{x}$-axis against the treatments included in the network on the $y$-axis [11]. Each point corresponds to three pieces of information: treatment, rank position, and probability of each ranking. The area in each circle is proportional to the ranking probability, and the number in each circle represents the probability for the corresponding treatment to rank at the specific position.

Figure S4 demonstrates the bubble plot for the ranking probabilities of the 12 longacting inhaled treatments for arrhythmia. This plot suggests that salmeterol/fluticasone has a $38.98 \%$ probability of being the safest and a $0.21 \%$ probability of being the least safe. Similarly, vilanterol/fluticasone has a $3.46 \%$ probability of ranking $1^{\text {st }}$ and a $68.59 \%$ probability of ranking $12^{\text {th }}$.

\section{SUCRA plots}

SUCRA plots [5], also known as 'cumulative ranking probability plots', show probabilities of a treatment amongst $k$ best treatments, where $k$ ranges from 1 to T. Salanti 
et al. [5] suggest summarizing the ranking probabilities using the SUCRA values (expressed in percentages) that can be calculated from the cumulative ranking curves. The larger the area under the curve, the better the treatment.

In Figure S5, we present the SUCRA values and curves for the 12 long-acting inhaled agents for arrhythmia [17]. These results show that the SUCRA for salmeterol/fluticasone of being the safest for arrhythmia is $74.80 \%$, whereas vilanterol/fluticasone has the least probability of being the best (SUCRA=14.10\%).

\section{Plots for multiple outcomes}

There are two graphical tools for multiple outcomes; scatterplots and the rank-heat plot (the new graphical tool we are proposing). A scatterplot can only be used when outcome data is available for the same treatments, whereas the rank-heat plot can be used regardless of whether outcome data are available for all treatments. Both plots can be produced for SUCRAs, P(best), or median/mean rankings.

\section{Scatterplot}

The relative ranking for two outcomes has been presented in two-dimensional scatterplots [6], which can be extended to three-dimensional plots presenting the treatment ranking across three outcomes. Clustering methods have been suggested to group the performance of treatments according to their efficacy and/or safety, using the cluster ranking plot [6].

Figure S6 shows the ranking of 15 serotonin $\left(5-\mathrm{HT}_{3}\right)$ receptor antagonists according to SUCRA values for nausea and vomiting in a cluster ranking plot. The different colors and circles represent the different groups of treatments according to their similarity with regard to their performance in both outcomes. For example, the cluster of treatments on the right upper corner (in blue) represents treatments that perform well in both outcomes, whereas the cluster of treatments close to the origin (in red) are the treatments that perform the worst on both outcomes (placebo in this case).

\section{Rank-heat plot}

The rank-heat plot is a novel approach for the visual presentation of the treatment hierarchy across multiple outcomes. A rank-heat plot includes $\mathrm{N}$ circles with the same center but different radii, where $\mathrm{N}$ is the number of outcomes. The area of each concentric circle is divided by the total number of treatments $\mathrm{T}$, and each sector is colored according to the ranking of the particular treatment at the corresponding outcome. The scale consists of the transformation of three colors (red, yellow and green) and ranges from the lowest to the highest value of the ranking statistic, such as $0 \%$ to $100 \%$ according to the SUCRA values. The red color corresponds to the smallest SUCRA value $(0 \%)$, values near the middle of the scale are yellow, and the green color corresponds to the highest SUCRA value $(100 \%)$. It should be noted that only the color of the sector is interpretable and that the area of the sector does not convey any information. 
Figure 1 displays the hierarchy of 8 treatments for type I diabetes across 3 outcomes (Figure 1a), as well the treatment order of $155-\mathrm{HT}_{3}$ agents across 5 outcomes (Figure 1b) using the rank-heat plot. Uncolored sectors suggest that data on that outcome was not reported for the particular treatment in the trials included in the NMA. Figure 1a suggests that glargine twice daily (bid) is most likely the the best treatment for severe hypoglycemia, whereas glargine once daily (od) performs well for both $\mathrm{A} 1_{\mathrm{C}}$ and weight gain outcomes. For severe hypoglycemia, detemir [od] is one of the best agents, but as the dosage frequency increases, the performance of detemir decreases. Overall, detemir[od/bid] performs best for weight gain. For $\mathrm{A} 1_{\mathrm{C}}$, detemir [od/bid] and detemir four times daily (qid) have a similar good performance, whereas detemir [od] performs worst among the three. In Figure 1b, granisetron+dexamethasone is most likely the most effective for preventing nausea, vomiting, and postoperative nausea and vomiting combined, but it performs worst for arrhythmia.

(Figure 1 here)

A rank-heat plot can also be presented using a grey scale of colors with dark grey corresponding to the smallest SUCRA value $(0 \%)$ and light grey corresponding to the highest SUCRA value (100\%). A star symbol in white sectors refer to treatments without data on the outcome within the circle.

(Figure 2 here)

The datasets for our illustrative examples and the $\mathrm{R}$ code used to create the rankheat plots are available in Texts S1 and S2 in Supporting Information. The rank-heat plot provides also the option of a colored version, where each color is associated with a different pattern (see Figure S7). This version of the rank-heat plot has been also tested for use by people with color blindness.

\section{Discussion}

Ranking statistics for treatments included in a NMA can be displayed in various graphs. A comparison of the methods according to their properties is shown in Table 1. We have proposed a new way to present the treatment ranking in NMA with multiple outcomes. A rank-heat plot is a graphical presentation of the NMA results and can be used to quickly recognize what are most likely the best and worst interventions with respect to their effectiveness and/or safety in a single or multiple outcome(s), which may increase interpretability. It can also identify treatments that have not been studied with regard to particular outcomes. Clinicians can use this information to discuss which agent is optimal across the different outcomes with their patients and caregivers, guideline developers can use this to inform their recommendations, as can policy makers decide about drug coverage. The novel approach may improve presentation and facilitate interpretation of findings. Hence, the rank-heat plot could be added to the preferred reporting items for systematic reviews and meta-analysis (PRISMA) guideline extention for NMA [10]. 
A limitation of the suggested graph is that it cannot display all of the ranking probabilities for each treatment and outcome at each position. However, the rank-heat plot is an efficient way to present the results of ranking statistics, particularly when a large amount of data is available. As well, it can be used to compare treatment ranking results across different statistical models. Heatmap plots can poorly discriminate between values close to each other, such as SUCRA $=90 \%$ and SUCRA=80\%. However, the rank-heat plot provides the option of including the exact values in each sector. Similar to all other approaches, all outcomes in the rank-heat plot have equal weights (i.e., no outcome preferences are taken into account) and no numerical summary of all outcomes is provided.

(Table 1 here)

Although some of the statistics examined here have inherent strengths and limitations [5, 18, 19] (e.g., the $\mathrm{P}$ (best) does not account for the uncertainty in the treatment effect estimates), our focus is on the graphical presentation of these statistics and we do not discuss their strengths and limitations. Our purpose is to provide an approach overcoming one of the key limitations of the current approaches, and more specifically to provide a strategy for easily displaying and understanding all of the available information on safety and effectiveness. In addition, we do not discuss the interpretability of the different graphical presentations; an area warranting further research. Finally, it is beyond the scope of this study to consider graphical ways of presenting the treatment effects and their uncertainty (e.g., forest plots) estimated in a NMA. It would be helpful to assess how investigators in previous studies report the NMA results and handle this complexity when more than two outcomes are evaluated, which would benefit from an extensive systematic review of all published NMAs. More importantly, research is needed to assess the understanding of the available approaches for presenting the treatment ranking by clinicians, guideline developers, and policy makers. This research is critical because different approaches may complicate inference and decision-making based on NMA findings. 


\title{
Authors' contributions
}

AAV, SES, AF and ACT conceived and designed the study. AF and AAV designed the code used for the analysis. AAV wrote the first draft manuscript and the other authors edited the manuscript.

\section{Acknowledgements}

AAV is funded by the CIHR Banting Postdoctoral Fellowship Program. SES is funded by a Tier 1 Canada Research Chair in Knowledge Translation. ACT is funded by a Drug Safety and Effectiveness Network/Canadian Institutes of Health Research New Investigator Award in Knowledge Synthesis.

\section{Competing interests}

Drs. Tricco A.C. and Straus S.E. are on the editorial board of the Journal of Clinical Epidemiology, but were not involved with the peer review process or decision for publication. The other authors have nothing to declare.

\begin{abstract}
Abbreviations
A1c: glycosylated hemoglobin, ACLI: aclidinium bromide, AZD3199: AZD3199 (ultra LABA), BECL/FORM: beclomethasone/formoterol, bid: twice daily, BUDE: budesonide, COPD: chronic obstructive pulmonary disease, DOLA: dolasteron, DOLA+DEX: dolasetron + dexamethasone, DOLA+DROP: dolasetron + droperidol IV, FLUT: fluticasone, FLUT/TIOT: fluticasone/tiotropium, FORM, formoterol, FORM/BUDE: formoterol/budesonide, FORM/TIOT/BUDE: formoterol/budesonide/tiotropium, FORM/MOME: formoterol/mometasone, FORM/TIOT: formoterol/tiotropium, GLYC: glycopyrronium bromide, GRAN: granisetron, GRAN+DEX: Granisetron + Dexamethasone, GRAN+DROP: dolasetron + droperidol IV, INDA: indacaterol, INDA/GLYC: indacaterol/glycopyrronium, INDA/TIOT: indacaterol/tiotropium, MOME: mometasone, NMA: network meta-analysis, Od: once daily, ONDA: ondansetron, ONDA+DEX: ondansetron + dexamethasone, ONDA+DROP: ondansetron + droperidol IV, ONDA+MET: Ondansetron + MetoclopramideIV, PALO: palonostetron, PALO+DEX: Palonosetron + Dexamethasone, P(best): Probability of being the best, PLAC: placebo, PONV: postoperative nausea and vomiting, RAMO: ramosteron, qid: four times daily, SAML: salmeterol, SALM/FLUT: salmeterol/fluticasone, SALM/TIOT: salmeterol/tiotropium, SUCRA: surface under the cumulative ranking curve, TIOT: tiotropium, TIOT/BUDE/FORM: tiotropium/budesonide/formoterol, TIOT/FLUT/SALM: tiotropium/ fluticasone /salmeterol, TIOT+Resp: Tiotropium Respimat (Soft Mist Inhaler), TRIAM: triamcinolone acetonide, TROP: tropisetron, UMEC: umeclidinium, VILA: vilanterol, VILA/FLUT: vilanterol/fluticasone, VILA/UMEC: vilanterol/umeclidinium
\end{abstract}




\section{References}

[1] Caldwell DM, Ades AE, Higgins JP. Simultaneous comparison of multiple treatments: combining direct and indirect evidence. BMJ. 2005;331:897-900.

[2] Higgins JP, Whitehead A. Borrowing strength from external trials in a meta-analysis. Statistics in medicine. 1996;15:2733-49.

[3] Lu G, Ades AE. Combination of direct and indirect evidence in mixed treatment comparisons. Statistics in medicine. 2004;23:3105-24.

[4] Nikolakopoulou A, Chaimani A, Veroniki AA, Vasiliadis HS, Schmid CH, Salanti G. Characteristics of networks of interventions: a description of a database of 186 published networks. PLoS ONE. 2014;9:e86754.

[5] Salanti G, Ades AE, Ioannidis JP. Graphical methods and numerical summaries for presenting results from multiple-treatment meta-analysis: an overview and tutorial. J Clin Epidemiol. 2011;64:163-71.

[6] Chaimani A, Higgins JP, Mavridis D, Spyridonos P, Salanti G. Graphical tools for network meta-analysis in STATA. PLoS One. 2013;8:e76654.

[7] Tan SH, Cooper NJ, Bujkiewicz S, Welton NJ, Caldwell DM, Sutton AJ. Novel presentational approaches were developed for reporting network meta-analysis. J Clin Epidemiol. 2014;67:672-80.

[8] Fadda V, Maratea D, Trippoli S, Messori A. Network meta-analysis. Results can be summarised in a simple figure. BMJ. 2011;342:d1555.

[9] Krahn U, Binder H, Konig J. A graphical tool for locating inconsistency in network meta-analyses. BMC Med Res Methodol. 2013;13:35.

[10] Hutton B, Salanti G, Caldwell DM, Chaimani A, Schmid CH, Cameron C, et al. The PRISMA Extension Statement for Reporting of Systematic Reviews Incorporating Network Meta-analyses of Health Care Interventions: Checklist and Explanations. Ann Intern Med. 2015;162:777-84.

[11] Hawkins N, Scott DA, Woods BS, Thatcher N. No study left behind: a network metaanalysis in non-small-cell lung cancer demonstrating the importance of considering all relevant data. Value Health. 2009;12:996-1003.

[12] Cipriani A, Furukawa TA, Salanti G, Geddes JR, Higgins JP, Churchill R, et al. Comparative efficacy and acceptability of 12 new-generation antidepressants: a multipletreatments meta-analysis. Lancet. 2009;373:746-58.

[13] Cipriani A, Barbui C, Salanti G, Rendell J, Brown R, Stockton S, et al. Comparative efficacy and acceptability of antimanic drugs in acute mania: a multiple-treatments metaanalysis. Lancet. 2011;378:1306-15.

[14] Tricco AC, Ashoor HM, Antony J, Beyene J, Veroniki AA, Isaranuwatchai W, et al. Safety, effectiveness, and cost effectiveness of long acting versus intermediate acting insulin for patients with type 1 diabetes: systematic review and network meta-analysis. BMJ. 2014;349:g5459.

[15] Tricco AC, Soobiah C, Blondal E, Veroniki AA, Khan PA, Vafaei A, et al. Comparative efficacy of serotonin (5-HT3) receptor antagonists in patients undergoing surgery: a systematic review and network meta-analysis. BMC medicine. 2015;13:136.

[16] Tricco AC, Soobiah C, Blondal E, Veroniki AA, Khan PA, Vafaei A, et al. Comparative safety of serotonin (5-HT3) receptor antagonists in patients undergoing surgery: a systematic review and network meta-analysis. BMC medicine. 2015;13:142.

[17] Tricco AC, Strifler L, Veroniki AA, Yazdi F, Khan PA, Scott A, et al. Comparative safety and effectiveness of long-acting inhaled agents for treating chronic obstructive 
pulmonary disease: a systematic review and network meta-analysis. BMJ open. 2015;5:e009183.

[18] Jansen JP, Trikalinos T, Cappelleri JC, Daw J, Andes S, Eldessouki R, et al. Indirect treatment comparison/network meta-analysis study questionnaire to assess relevance and credibility to inform health care decision making: an ISPOR-AMCP-NPC Good Practice Task Force report. Value Health. 2014;17:157-73.

[19] Kibret T, Richer D, Beyene J. Bias in identification of the best treatment in a Bayesian network meta-analysis for binary outcome: a simulation study. Clin Epidemiol. 2014;6:451-60. 


\section{Tables and Figure captions}

Table 1. Overview of the properties of the graphical tools presenting the ranking statistics for a single or multiple outcomes

\begin{tabular}{|c|c|c|c|c|c|c|c|c|}
\hline & \multicolumn{6}{|c|}{ Single Outcome } & \multicolumn{2}{|c|}{ Multiple Outcomes } \\
\hline & $\begin{array}{l}\text { Pie } \\
\text { chart }\end{array}$ & $\begin{array}{l}\text { Rank } \\
\text { chart }\end{array}$ & Rankogram & $\begin{array}{l}\text { Stacked } \\
\text { bar plot }\end{array}$ & $\begin{array}{c}\text { Bubble } \\
\text { plot }\end{array}$ & $\begin{array}{l}\text { SUCRA } \\
\text { plots }\end{array}$ & $\begin{array}{c}\text { Scatter- } \\
\text { plot }\end{array}$ & $\begin{array}{c}\text { Rank- } \\
\text { heat plot }\end{array}$ \\
\hline $\begin{array}{c}\mathrm{P} \text { (best) can be } \\
\text { displayed }\end{array}$ & $\checkmark$ & $\checkmark$ & $\checkmark$ & $\checkmark$ & $\checkmark$ & $\checkmark$ & $\checkmark$ & $\checkmark$ \\
\hline $\begin{array}{c}\text { SUCRA can be } \\
\text { displayed }\end{array}$ & $\checkmark$ & $\checkmark$ & -- & -- & -- & $\checkmark$ & $\checkmark$ & $\checkmark$ \\
\hline $\begin{array}{c}\text { Mean/Median } \\
\text { ranks can be } \\
\text { displayed }\end{array}$ & $\checkmark$ & $\checkmark$ & -- & -- & -- & & $\checkmark$ & $\checkmark$ \\
\hline $\begin{array}{l}\text { All ranking } \\
\text { probabilities (or } \\
\text { cumulative } \\
\text { probabilities) can } \\
\text { be displayed }\end{array}$ & -- & -- & $\checkmark$ & $\checkmark$ & $\checkmark$ & & -- & -- \\
\hline $\begin{array}{l}\text { Can display the } \\
\text { ranking of many } \\
(>15) \text { treatments }\end{array}$ & -- & $\checkmark$ & $\checkmark$ & -- & $\infty$ & $\checkmark$ & $\checkmark$ & $\checkmark$ \\
\hline $\begin{array}{c}\text { The exact } \\
\text { numerical values } \\
\text { of the ranking } \\
\text { statistics can be } \\
\text { presented }\end{array}$ & $\checkmark$ & -- & $\checkmark$ & & $\checkmark$ & -- & $\checkmark$ & $\checkmark$ \\
\hline $\begin{array}{c}\text { Can identify } \\
\text { treatments that } \\
\text { have been studied } \\
\text { only in certain } \\
\text { outcomes }\end{array}$ & -- & -- & & -- & -- & -- & -- & $\checkmark$ \\
\hline $\begin{array}{l}\text { More than } 3 \\
\text { outcomes can be } \\
\text { displayed }\end{array}$ & -- & & -- & -- & -- & -- & -- & $\checkmark$ \\
\hline $\begin{array}{l}\text { Can be produced } \\
\text { when different } \\
\text { treatments are } \\
\text { included in the } \\
\text { studied outcomes }\end{array}$ & $\checkmark$ & $\checkmark$ & $\checkmark$ & $\checkmark$ & $\checkmark$ & $\checkmark$ & -- & $\checkmark$ \\
\hline
\end{tabular}

Figure 1. Rank-heat plots of 8 treatments studied in patients with type 1 diabetes in three different outcomes (a) and 15 serotonin $\left(5-\mathrm{HT}_{3}\right)$ receptor antagonists for patients undergoing surgery in five outcomes (b). Each sector is colored according to the SUCRA value of the corresponding treatment and outcome. The scale consists of the transformation of three colors red (0\%), yellow (50\%), and green $(100 \%)$. In (b) each sector includes also the SUCRA value corresponding to the specific treatment and outcome. Uncolored sectors show that the underlying treatment was not included in the NMA for the particular outcome.

Figure 2. Rank-heat plot of 30 COPD agents ordered according to their SUCRA values in five different outcomes. Each sector is colored according to the SUCRA value of the corresponding treatment and outcome. A dark grey corresponds to the smallest SUCRA value (0\%) and a light 
grey corresponds to the highest SUCRA value (100\%). Uncolored sectors including a start symbol show that the underlying treatment was not included in the NMA for the particular outcome.

Abbreviations in Figures: A1c: glycosylated hemoglobin, ACLI: aclidinium bromide, AZD3199: AZD3199 (ultra LABA), BECL/FORM: beclomethasone/formoterol, bid: twice daily, BUDE: budesonide, COPD: chronic obstructive pulmonary disease, DOLA: dolasteron, DOLA+DEX: dolasetron + dexamethasone, DOLA+DROP: dolasetron + droperidol IV, FLUT: fluticasone, FLUT/TIOT: fluticasone/tiotropium, FORM, formoterol, FORM/BUDE: formoterol/budesonide, FORM/TIOT/BUDE: formoterol/budesonide/tiotropium, FORM/MOME: formoterol/mometasone, FORM/TIOT: formoterol/tiotropium, GLYC: glycopyrronium bromide, GRAN: granisetron, GRAN+DEX: Granisetron + Dexamethasone, GRAN+DROP: dolasetron + droperidol IV, INDA: indacaterol, INDA/GLYC: indacaterol/glycopyrronium, INDA/TIOT: indacaterol/tiotropium, MOME: mometasone, Od: once daily, ONDA: ondansetron, ONDA+DEX: ondansetron + dexamethasone, ONDA+DROP: ondansetron + droperidol IV, ONDA+MET: Ondansetron + MetoclopramideIV, PALO: palonostetron, PALO+DEX: Palonosetron + Dexamethasone, PLAC: placebo, PONV: postoperative nausea and vomiting, RAMO: ramosteron, qid: four times daily, SAML: salmeterol, SALM/FLUT: salmeterol/fluticasone, SALM/TIOT: salmeterol/tiotropium, SUCRA: surface under the cumulative ranking curve, TIOT: tiotropium, TIOT/BUDE/FORM: tiotropium/budesonide/formoterol, TIOT/FLUT/SALM: tiotropium/ fluticasone /salmeterol, TIOT+Resp: Tiotropium Respimat (Soft Mist Inhaler), TRIAM: triamcinolone acetonide, TROP: tropisetron, UMEC: umeclidinium, VILA: vilanterol, VILA/FLUT: vilanterol/fluticasone, VILA/UMEC: vilanterol/umeclidinium 


\section{Supporting Information}

\section{Text S1}

Datasets used for the three empirical examples (type I diabetes, serotonin (5- $\left.\mathrm{HT}_{3}\right)$ receptor antagonists for patients undergoing surgery, Chronic Obstructive Pulmonary Disease).

\section{Text S2}

$\mathrm{R}$ code for rank-heat plot, along with a help file.

\section{Figures}

Figure S1. Pie chart and rank chart (b) representing the probability for each treatment being the best in the chronic obstructive pulmonary disease (COPD) arrhythmia network.

Figure S2. Rankograms for the 12 chronic obstructive pulmonary disease (COPD) treatments studied in arrhythmia outcome.

Figure S3. Stacked bar plot for the 12 chronic obstructive pulmonary disease (COPD) treatments for arrhythmia outcome.

Figure S4. Bubble plot for the 12 chronic obstructive pulmonary disease (COPD) treatments for arrhythmia outcome.

Figure S5. SUCRA plots for the 12 chronic obstructive pulmonary disease (COPD) treatments for arrhythmia outcome.

Figure S6. Cluster ranking scatterplot for 15 serotonin $\left(5-\mathrm{HT}_{3}\right)$ receptor antagonists according to SUCRA values for nausea (x-axis) and vomiting (y-axis) outcomes for patients undergoing surgery.

Figure S7. Rank-heat plot of 15 serotonin $\left(5-\mathrm{HT}_{3}\right)$ receptor antagonists for patients undergoing surgery in five outcomes. Each sector is colored according to the SUCRA value of the corresponding treatment and outcome. The scale consists of the transformation of three colors red $(0 \%)$, yellow (50\%), and green (100\%), and each color is associated with a different pattern. Uncolored sectors show that the underlying treatment was not included in the NMA for the particular outcome. 


\section{A. Type I diabetes}

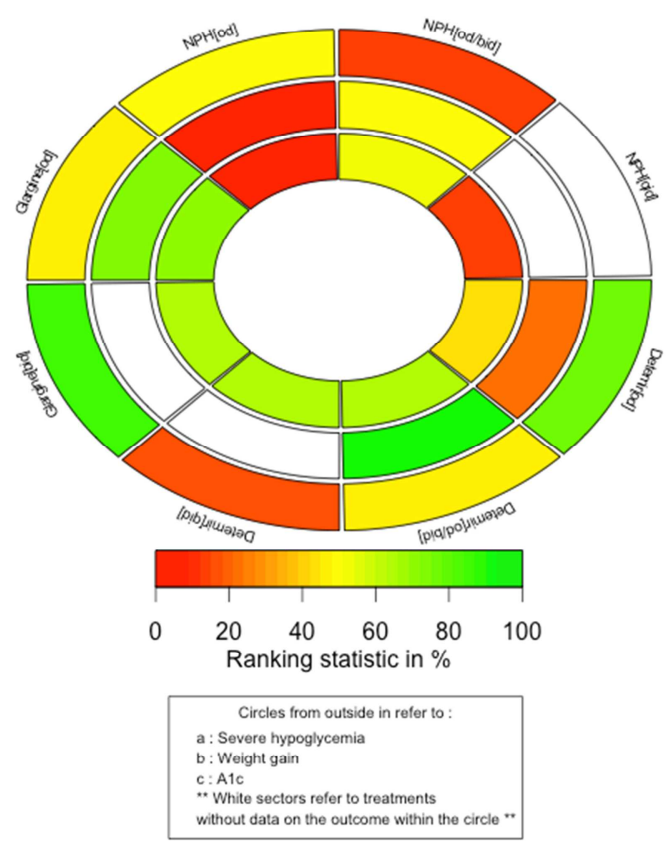

B. 5-HT3 surgery

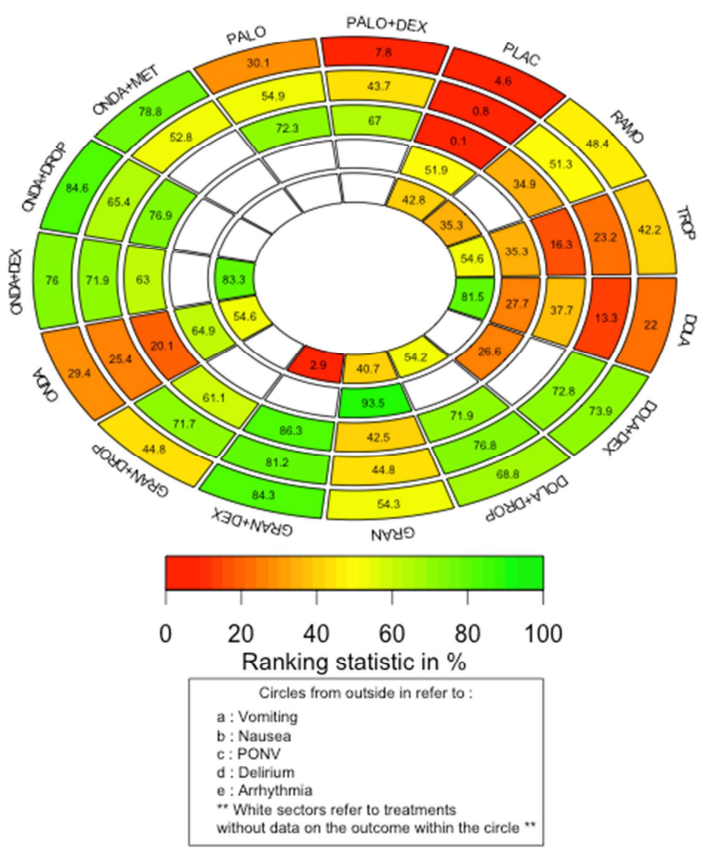




\section{COPD - Rank-heat plot based on SUCRA}

\begin{tabular}{|c|}
\hline Treatment \\
\hline $1: \mathrm{ACLI}$ \\
\hline $2:$ AZD3199 \\
\hline 3: BECL/FORM \\
\hline $4:$ BUDE \\
\hline $5:$ FLUT \\
\hline 6: FLUT/TIOT \\
\hline $7:$ FORM \\
\hline 8:FORM/BUDE \\
\hline $\begin{array}{l}9: \text { FORM/BUDE/TIOT } \\
10: \text { FORM/MOME }\end{array}$ \\
\hline $11:$ FORM/TIOT \\
\hline $12:$ GLYC \\
\hline $13:$ GSK961081 \\
\hline $14:$ INDA \\
\hline $15:$ INDA/GLYC \\
\hline 16 : INDATIOT \\
\hline $17:$ MOME \\
\hline 18 : Placebo \\
\hline $19:$ SALM \\
\hline $20:$ SALM/FLUT \\
\hline 21 : SALM/TIOT \\
\hline $22:$ TIOT \\
\hline $23:$ TIOT/BUDE/FORM \\
\hline 24 : TIOT/FLUT/SALM \\
\hline $25:$ TIOT+Resp \\
\hline 26 : TRIAM \\
\hline 27 : UMEC \\
\hline 28 : VILA \\
\hline $29:$ VILA/FLUT \\
\hline 30 : VILAJUMEC \\
\hline
\end{tabular}

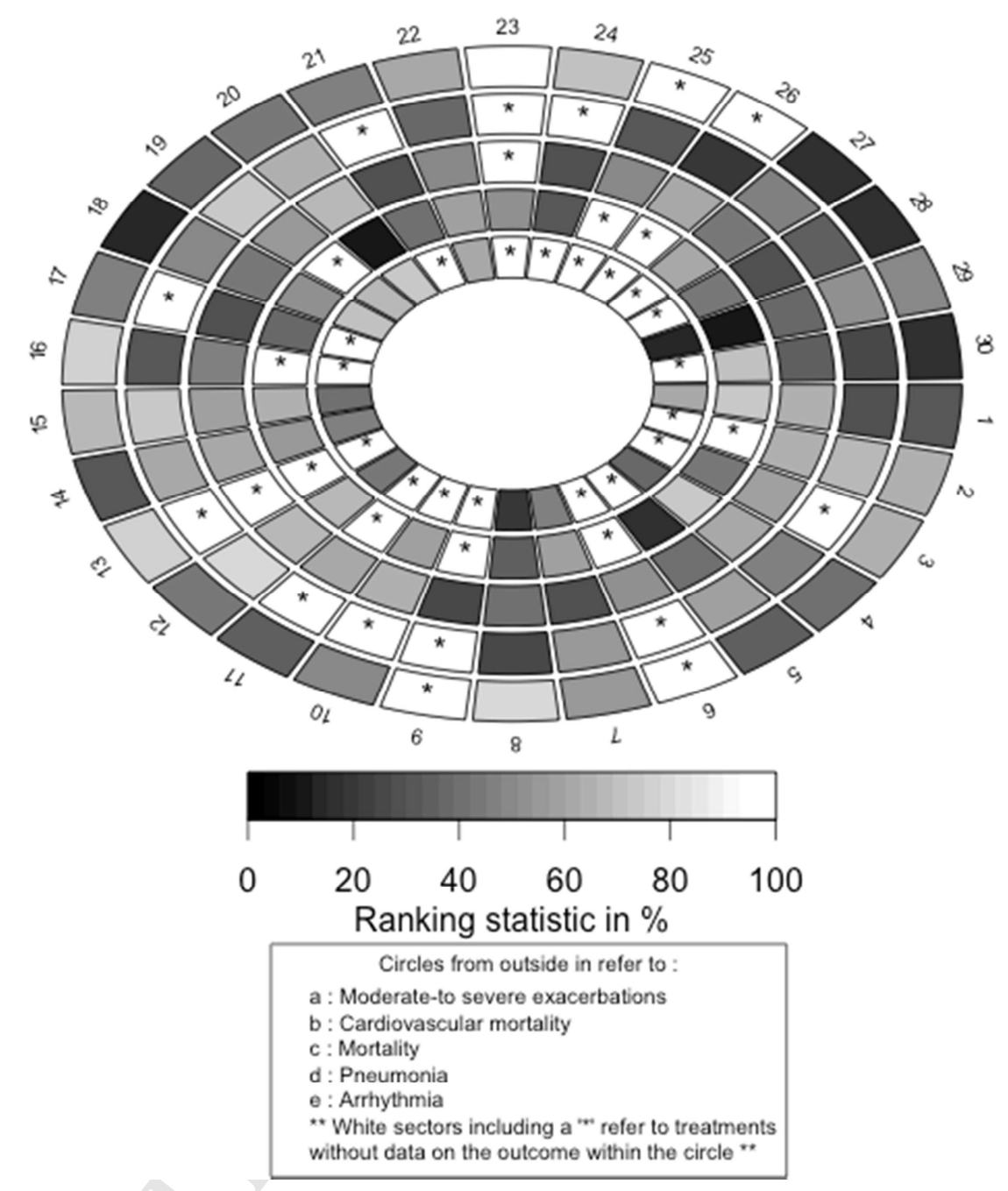

